\title{
A review of nanoparticle functionality and toxicity on the central nervous system
}

\author{
Z. Yang ${ }^{1}$, Z. W. Liu ${ }^{1}$, R. P. Allaker ${ }^{2}$, P. Reip ${ }^{3}$, J. Oxford ${ }^{2}$, \\ Z. Ahmad ${ }^{4}$ and G. Ren ${ }^{5, *}$ \\ ${ }^{1}$ School of Medical Science, Nankai University, Tianjin, China \\ ${ }^{2}$ Queen Mary University of London, Barts and The London School of Medicine and Dentistry, \\ Institute of Dentistry, Newark Street, London E1 2AT, UK \\ ${ }^{3}$ Intrinsiq Materials Ltd, Farnborough, Hants GU14 OLX, UK \\ ${ }^{4}$ Department of Mechanical Engineering, University College London, Torrington Place, \\ London WC1E 7JE, UK \\ ${ }^{5}$ School of Engineering and Technology, University of Hertfordshire, Hatfield AL10 9AB, UK
}

\begin{abstract}
Although nanoparticles have tremendous potential for a host of applications, their adverse effects on living cells have raised serious concerns recently for their use in the healthcare and consumer sectors. As regards the central nervous system (CNS), research data on nanoparticle interaction with neurons has provided evidence of both negative and positive effects. Maximal application dosage of nanoparticles in materials to provide applications such as antibacterial and antiviral functions is approximately $0.1-1.0 \mathrm{wt} \%$. This concentration can be converted into a liquid phase release rate (leaching rate) depending upon the host or base materials used. For example, nanoparticulate silver $(\mathrm{Ag})$ or copper oxide $(\mathrm{CuO})$-filled epoxy resin demonstrates much reduced release of the metal ions $\left(\mathrm{Ag}^{+}\right.$or $\left.\mathrm{Cu}^{2+}\right)$ into their surrounding environment unless they are mechanically removed or aggravated. Subsequent to leaching effects and entry into living systems, nanoparticles can also cross through many other barriers, such as skin and the blood-brain barrier (BBB), and may also reach bodily organs. In such cases, their concentration or dosage in body fluids is considered to be well below the maximum drug toxicity test limit $\left(10^{-5} \mathrm{~g} \mathrm{ml}^{-1}\right)$ as determined in artificial cerebrospinal solution. As this is a rapidly evolving area and the use of such materials will continue to mature, so will their exposure to members of society. Hence, neurologists have equal interests in nanoparticle effects (positive functionality and negative toxicity) on human neuronal cells within the CNS, where the current research in this field will be highlighted and reviewed.
\end{abstract}

Keywords: nanoparticles; central nervous system; functionality; toxicity

\section{INTRODUCTION}

The advent of nanoparticle systems has had a major impact in a host of scientific areas, opening up new capabilities and functionalities across a wide range of applications. The properties of nanomaterials can differ from those demonstrated by their bulk forms and, in some cases, give completely unexpected physical and chemical properties. For this reason many industries and manufacturers are now introducing nanomaterials and nanotechnologies in their mainstream products so as to exploit these new capabilities.

*Author for correspondence (g.g.ren@herts.ac.uk).

One contribution to a Theme Supplement 'Scaling the heightschallenges in medical materials: an issue in honour of William Bonfield, Part I. Particles and drug delivery'.
Many types of nanomaterials are also flourishing in medical science and technological areas while related research and applications are exploring potentials in biosensors, biomaterials, tissue engineering, DNA modification, drug and drug-delivery systems (Chen et al. 2006; Lu et al. 2008; Kim et al. 2009; Sun et al. 2009; Kirkpatrick \& Bonfield 2010). Another area which has benefited from these advances is microbiology, where the inhibitory effect of nanoparticles on microbes can be seen as a tool to combat and control outbreaks of disease. However the effect on microbes must also be viewed carefully as it demonstrates the potential effect nanoparticle systems can have on living systems; the relatively modest information on nanoparticle toxicity in various human systems means the issue of safety still remains 


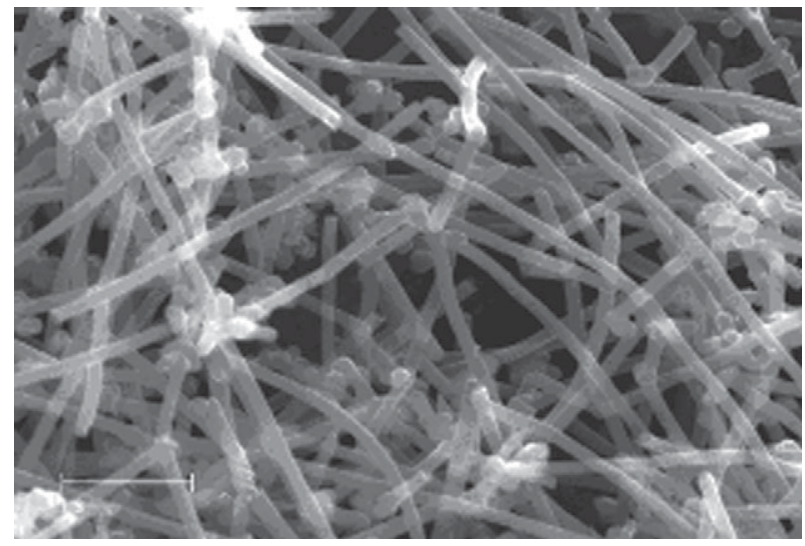

Figure 1. Scanning electron micrograph (SEM) showing multi-wall carbon nanotubes.

incomplete. Several studies have highlighted this issue further. For example, it has been shown that manmade nanomaterials possess highly activated surfaces which are capable of inducing carcinogens, mutagens or cytotoxic activity (Seemayer et al. 1990; Seaton et al. 2010). Coupled to these surface properties is the direct size comparison; for example, nanoparticles are 100 times smaller than normal red blood cells, which increases the potential for interaction, and there is evidence that nanoparticles interact with proteins, DNA (Seeman 2006), lung cells and viruses. Hence, understanding nanoparticle interaction with living cells and other biological systems is critical, especially as the potential and exploitation of such technologies is rapidly gathering pace, requiring healthcare professionals and the public in general to be in closer contact with such materials. For example, metallic nanoparticle systems are now readily used for their anti-microbial properties in everyday products ranging from deodorants to personalized computer devices (Allaker \& Ren 2008).

As was the case with nuclear technology, the personal computer boom and GM crops/animals, more than 68 per cent of people now believe that nanotechnology 'would make things better in the future' (Royal Academy of Engineering 2004).

One class of material which has had such impact is carbon nanotubes (CNTs). Single-wall (approx. $10 \mathrm{~nm}$ in diameter) or multi-wall CNTs with extremely high aspect ratios (as high as 1000) have a much lower percolation threshold. They are composed of many nanotubes and are chemically bonded together, possessing a highly activated surface and exhibiting superior strength, rigidity and electrical conductivity. Figure 1 shows standard industrial grade multi-wall CNTs used in high-performance conventional batteries (large scale).

Biocompatible and biomedical materials such as hydroxyapatite (HA) and carbon-coated titanium alloys for bone and hip replacements release debris of nanometre- and micrometre-scaled particles from metallic implants owing to host environment friction, and several studies have pointed out the potential risks in such bone repair and replacement (Moore et al. 2001). Nanoparticles such as $\mathrm{SiO}_{x}$ and CNTs may also act similarly with neurotoxins which affect the central or peripheral nervous system. Although the most common neurotoxin is alcohol, others include heavy metals, organic solvents and rarer 'designer' drugs (Cole \& Sumnall 2003). As nanoscaled substances have an active surface, they may cause or produce acute neurological complications, or subacute or chronic illnesses. Neuron synaptic transmission and neuron cell membrane with the ionic channels for $\mathrm{Ca}^{2+}, \mathrm{Na}^{+}, \mathrm{K}^{+}$and $\mathrm{Cl}^{-}$may also provide a route of entry for CNTs or smaller nanoparticles.

Although there are numerous biological systems which can be investigated for such nanoparticle interactions, this review focuses on studies related to the functionality and toxicity of anti-viral/antimicrobial nanoparticles in the central nervous system (CNS). The current findings show that both negative and positive effects are observed by using selected nanoparticles, typically deployed as anti-bacterial/viral compositions $(0.1-1.0 \% \mathrm{w} / \mathrm{w} ; \mathrm{Xu}$ et al. 2009). Figure 2 shows typical copper oxide $(\mathrm{CuO})$ nanoparticles (figure 2a) and agglomerated silver nanoparticles (figure $2 b$ ) that are used in such studies as model anti-microbial nanomaterials, which provide better anti-bacterial capabilities than their bulk material (Raffi et al. 2008; figure 3).

\subsection{Important issues of nanoparticle toxicity in general}

A selection of findings on nanoparticle toxicity on a host of living systems can be illustrated to elucidate these points, and also advocate the need to understand these interactions in greater detail. For example, some studies on rats have shown that 15 per cent of the sample population died within $24 \mathrm{~h}$ due to blockage of the airways as a result of carbon nanotubes being injected into their lungs (Lecoanet et al. 2004; Warheit et al. 2004). More of a concern is the effect observed from micro- and/or nanoscaled debris of artificial hip replacements as there is a growing demand for such biomaterials (e.g. implantable devices). These loose particulates arise as a result of friction, and travel into the blood stream and eventually lead to the formation of a thrombus (De Jong \& Borm 2008). There is also evidence to suggest migration of particles into organs (liver and the spleen) from similar prostheses (Gatti et al. 2004). Moving away from implantable devices, there is a risk posed from inhalation. Research has demonstrated that radio-labelled nanoparticles can reach the blood stream within $60 \mathrm{~s}$ via inhalation; and the liver within $60 \mathrm{~min}$ (Chunfu et al. 2004).

The current assumption is that smaller sized and highly activated nanoparticles (such as silica featured as hydrophilic, hydrophobic or even amphiphilic) can be taken up by human membranes. However, no response or signal is initiated that leads to the rejection of the particles, and these pass through the membrane passively. Potential health hazards related to such particles are the adsorption and enrichment of various poisonous substances (metals, dioxins, combined with hydrogen chloride $(\mathrm{HCl})$, hydrofluoric acid $(\mathrm{HF})$ on the particle phase which possess a much larger surface area (Robichaud et al. 2005)). Tetra-ethyl lead 


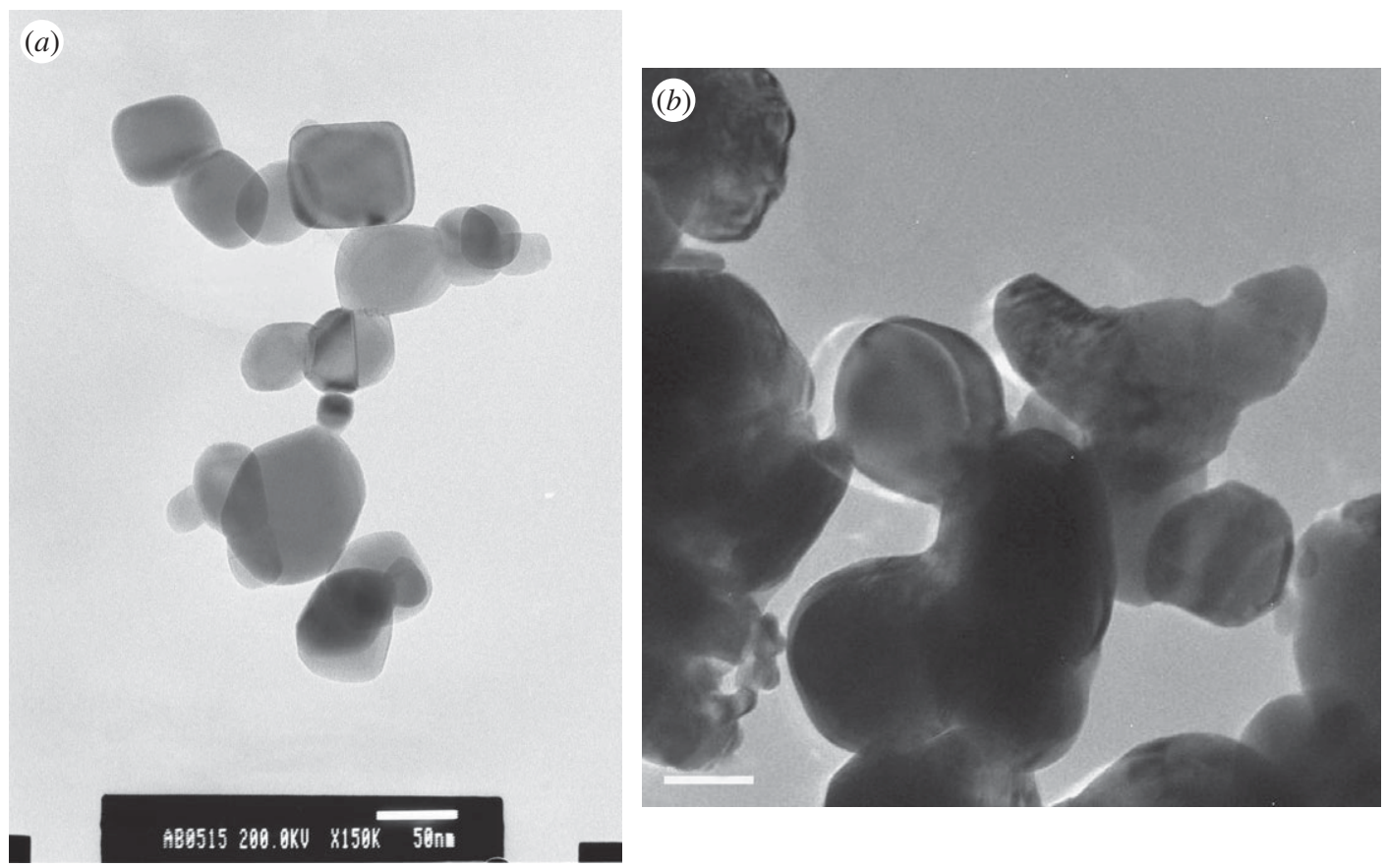

Figure 2. Transmission electron micrograph (TEM) of (a) CuO nanoparticles (QinetiQ Nanomaterials Ltd) and (b) agglomerated silver nanoparticles.

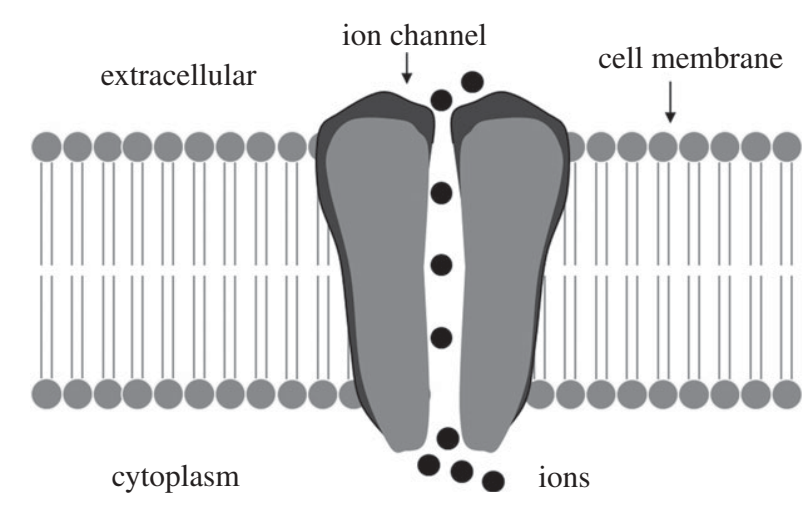

Figure 3. Neuron synaptic transmission and neuron cell membrane with passes for $\mathrm{Ca}^{2+}, \mathrm{Na}^{+}, \mathrm{K}^{+}$and $\mathrm{Cl}^{-}$(interactive physiology), where carbon nanotubes or smaller nanoparticles might be able to pass through easily.

$\left(\mathrm{PbC}_{8} \mathrm{H}_{20}\right)$, generated by lead petrol (4 Star) from car exhausts, once inhaled could be accumulated in the human brain.

This review considers three key elements of the toxicity screening methodologies or strategies covering physico-chemical characteristics, in vitro assays (cellular and non-cellular), and in vivo assays relevant to CNS cells. In particular, the review intends to concentrate on introducing the current techniques of drug in vitro and in vivo toxicology test methods into nanoparticle toxicology test methods by using CNS cells. These could be considered to determine proposed possibilities that the biological activity of nanoparticles can depend on physico-chemical parameters; however, they are not routinely being considered in toxicity screening studies because of the complexities of the tests of physico-chemical properties of nanoparticles, as recognized by many leading toxicity researchers
(Oberdörster et al. 2005; Wang et al. 2009). Although the functionality of nanoparticles is closely linked to their physical status and properties such as the particle morphology, particle interactions of agglomeration and aggregation, this paper is mainly concerned with the identified results of biological interactions between the current industrial nanoparticles and CNS cells.

The general interaction between physical properties and biological functionalities have been investigated and clearly highlighted by Oberdörster et al. (2005) on the basis of physico-chemical interactions with biological cells such as liver, blood, lung, macrophages, spleen and the immune system, CNS and neurons and skin, etc. The importance of physico-chemical properties has been emphasized again in the understanding of the toxic effects on biological cells, which include particle size and size distribution, agglomeration state, shape, crystal structure, chemical composition, surface area, surface chemistry, surface charge, and porosity.

While the size aspect of nanoparticles attracts considerable and rapidly growing attention to several industries, the chemical aspect of the materials should not be overlooked as this has been shown to be an important aspect in several nanomaterial-cell interactions (Thian et al. 2008). This review focuses on nanoparticle functionality with a broad view on materials falling into the nanomaterials range. However, materials chemistry will also have an impact; for example, it has been shown that silver nanoparticles are more anti-bacterial than copper nanoparticles.

\section{NEURON CELLS AND CENTRAL NERVOUS SYSTEM}

Neurons are nerve cells that, together with neuroglial cells, constitute the nervous tissue making up the nervous system. A neuron consists of a nerve cell body 
(or soma), axon and dendrites. Neurons receive nerve signals (action potentials), integrate action potentials, and transmit the signals to other neurons. Although the human nervous system is much more specialized and complicated than that of lower animals, the structure and function of neurons is essentially the same in all animals. In vitro systems to study the effects of particles on the nervous system have included neuron and nanoparticle cultures to determine the effects on neuronal functions (Oberdörster et al. 2005).

Ion channels are transmembrane proteins that mediate passive transport of ions, and the channels underlie a broad range of the most basic biological processes, from excitation and signalling to secretion and absorption. Studies of ion channels provide useful and informative clues for understanding the biophysics and pharmacology of these important and ubiquitous membrane proteins. There are many kinds of ion channels, such as sodium channels, calcium channels and potassium channels in rat models e.g. CA1 hippocampal neurons. Voltage-gated potassium $\left(\mathrm{K}^{+}\right)$channels can play crucial roles in regulating a variety of cellular processes in both excitable and non-excitable cells, such as setting and re-setting membrane potential, action potential duration, the delay between a stimulus and the first action potential and discharge patterns.

Further research has been carried out using metal nanoparticles such as $\mathrm{Ag}, \mathrm{Cu}$ and $\mathrm{Mn}$ on P12 brain cells to investigate potential neurotoxicity (Wang et al. 2009).

\subsection{Nanoparticles' interaction with the central nervous system}

Nanoparticles have shown biological functions such as killing pathogenic bacteria and viruses (e.g. flu), but research has also shown that nanoparticles may produce adverse effects (dose related) in human cells on contact. Human neural cells, such as hippocampal cells in the CNS, are the most sensitive and delicate cells in bioorganisms, and are responsible for brain functions and emotions. They are vulnerable to ischaemia, oxygen deficiency and external factors. One of the great concerns in science and technological development in the twenty-first century is that nanoparticles may produce potential functional and toxicity effects on human neural cells owing to their ability to pass through biological membranes (Brooking et al. 2001).

The blood-brain barrier (BBB) is a separation of circulating blood and cerebrospinal fluid (CSF) maintained by the choroid plexus in the CNS, which results from the selectivity of the tight junctions between endothelial cells in CNS vessels that restrict the passage of solutes. At the interface between blood and brain, endothelial cells and associated astrocytes are stitched together by tight junctions. Endothelial cells restrict the diffusion of microscopic objects and large or hydrophilic molecules into the CSF, while allowing the diffusion of small hydrophobic molecules (e.g. $\mathrm{O}_{2}$, hormones, $\mathrm{CO}_{2}$ ). Cells associated with the BBB actively transport metabolic products such as glucose across the barrier with specific proteins (Seidner et al. 1998).
Exposure to nanoparticles (such as Ag) in the body is also becoming increasingly widespread through antibacterial fabrics and coatings. However, effects from the presence (or even accumulation) of metal nanoparticles in the brain and through the BBB have not yet been fully studied. Small-sized particles have better mobility and it is expected that the transportation of nanoparticles across the $\mathrm{BBB}$ is possible either by passive diffusion or by carrier-mediated endocytosis (Hoet et al. 2004). In addition, nanoparticles may be taken up directly into the brain by trans-synaptic transport (Oberdörster 2004). For example, Ag nanoparticles can enter via the BBB (Panyala et al. 2008) and accumulate in different regions of the brain (Rungby \& Danscher 1983), and this may be beneficial for drug delivery, but may also pose a risk to the patient (Sarin et al. 2008; Muthu \& Singh 2009). It has also been reported that nanoparticle exposure can induce impairments to normal neurons (Tang et al. 2008), microglia (Au et al. 2007) and even aggravate the process of brain pathology (Sharma \& Sharma 2007). Ion channels play an important role in cell viability and functionality, especially in the CNS, which serve as a subtle indicator of the condition and viability of the cells.

Voltage-gated sodium currents determine a large number of neuronal properties, such as influencing action potential generation and the propagation of action potentials to synapse terminals. The local depolarization of neurons may also be affected by the existence of nanoparticles. However, what plays a key role remains to be determined in the transportation of amino acid neurotransmitters (e.g. aminobutyric acid (GABA)) and monoamines (i.e. dopamine (DA), norepinephrine, and serotonin). In addition, mutations may also cause changes in voltage-gated $\mathrm{Na}^{+}$channels, which are associated with a number of neurological diseases, including spontaneous epilepsy and pain conditions, and have been implicated in various psychiatric disorders (Meisler \& Kearney 2005; Guo et al. 2008).

The effective nanoparticle content used in applications $(0.1-1 \% \mathrm{w} / \mathrm{w})$ could be well below the toxicity dosage limit by the time nanoparticles reach the CNS from point of contact. This estimation takes into account the fact that released nanoparticles/ions also need to enter the body, then cross the BBB and finally reach the CNS. Most of the nanoparticle release rates from work carried out on solid matrix-particle composites (i.e. epoxy resins, as shown in figure 4) display the release range of ion/particle concentration to be less than $10^{-5} \mathrm{~g} \mathrm{ml}^{-1}$, which is the minimum non-effective dosage for all the CNS neuron cell tests (drug toxicity tests are around $10^{-6} \mathrm{~g} \mathrm{ml}^{-1}$ ). These nanoparticle neuron tests also take into account several types of nanoparticles, e.g. $\mathrm{Ag}, \mathrm{CuO}, \mathrm{ZnO}, \mathrm{TiO}_{2}$ ( $\mathrm{Xu}$ et al. 2009; Zhao et al. 2009; Liu et al. 2010). Since metallic particle systems are being used in a host of contact applications such as computers, paints and clothing, research into this area and further parametric variables needs to be considered (e.g. exposure, contact time, strength of binding and weight loading).

Voltage-gated sodium current is responsible for modifying the excitability of neuronal cells and neuronal activity and function in the CNS. Therefore, potential 


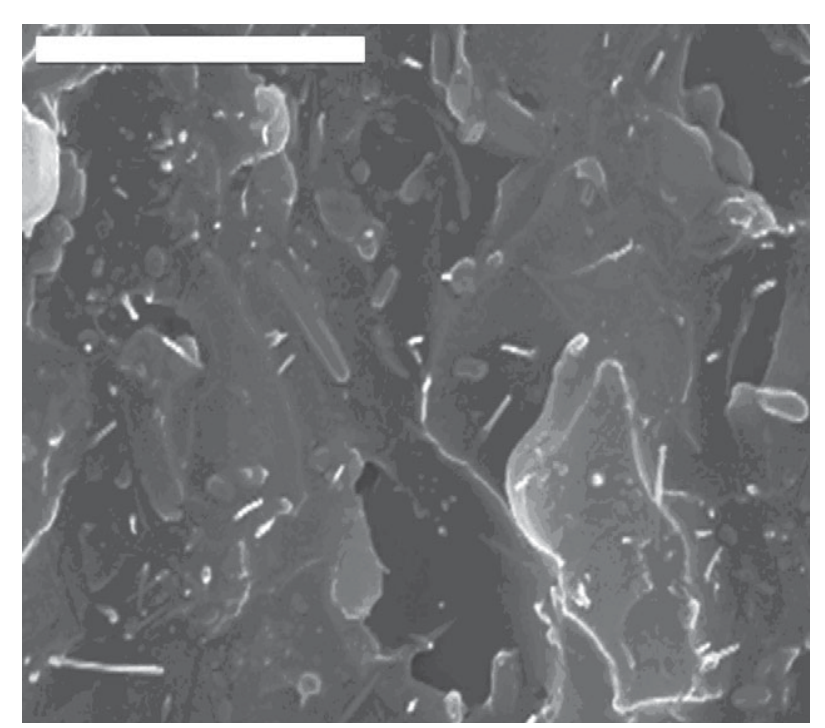

Figure 4. Scanning electron micrograph (SEM) of carbon nanotubes reinforced with epoxy resin (scale bar, $5 \mu \mathrm{m}$ ).

modulation of the current by nanometal particles would be expected, leading to alterations in functionality. Some reports have shown that nanoparticles can impair cell function and even induce certain cell death (Shin et al. 2007; Cha et al. 2008; Tang et al. 2008). In recent studies on the neurotoxicity of metallic nanoparticles, a neuro-endocrine cell line (PC-12 cells) was exposed to nanoparticles such as Ag $\left(5 \times 10^{-5} \mathrm{~g} \mathrm{ml}^{-1}\right)$, which reduced the level of DA. It was also found that $\mathrm{Ag}$ nanoparticles were more toxic than manganese (Mn) nanoparticles to particular cells (Hussain et al. 2006a). These findings suggest that $\mathrm{Ag}$ and other nanoparticles might have significant pathological consequences for the brain of mammalians while enhancing or inhibiting some particular functionality (figure 5).

Nanoparticles have potential functionality and toxic effects on human neuron cells since they can pass through biological membranes (Brooking et al. 2001). It is known that the biological half-life of silver in the CNS is longer than that in other organs, suggesting that there may be some significant physiological functions, consequences and risks to the brain due to prolonged exposure.

However, the effects from the presence (or even accumulation) of such particles, especially $\mathrm{Ag}$, in the CNS are not very well documented.

\section{CURRENT RESEARCH ADVANCES IN NANOPARTICLE AND NEURON CELL INTERACTION}

\subsection{The neurotoxicity research of nanoscaled materials in vivo}

To investigate the potential effects of nanomaterials on the brain, some in vivo tests have been carried out on different animal models. Nanoparticles $(50 \mathrm{~nm})$ of silica-coated cobalt ferrite were found in the brain after being administered via an intravenous injection

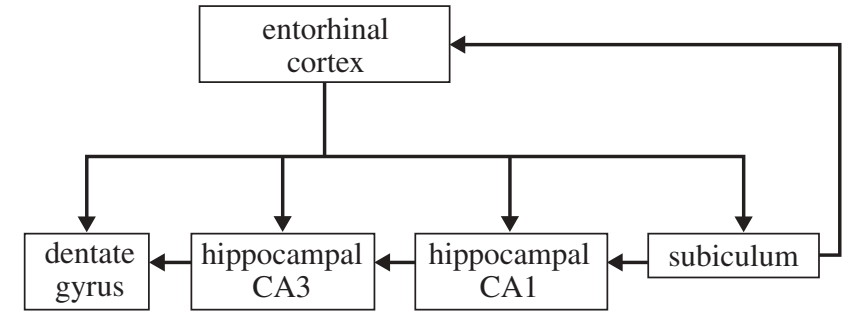

Figure 5. Schematic of hippocampal pathways.

in mice (Kim et al. 2006). In another study, F344 female rats received single or multiple exposures to 20 , 100 and $1000 \mathrm{~nm}$ latex fluorospheres by intravenous injection or oral pharyngeal aspiration into the airways. In this instance, the $20 \mathrm{~nm}$ spheres were not detected in the brain; however, the $100 \mathrm{~nm}$ spheres were detected in the CNS $24 \mathrm{~h}$ after administration. The $1000 \mathrm{~nm}$ spheres were detected for up to 28 days and were no longer found in the brain after this time point (Sarlo et al. 2009). Although this study utilized the same material (latex) for the various particle sizes, modest consideration was granted for material physico-chemical properties and it would not be representative if other materials, e.g. other polymers, metals, metal oxides, ceramic composites, CNTs, etc., were to be used in the same tests.

In addition, maternal exposure of mice to $\mathrm{TiO}_{2}$ nanoparticles may affect the expression of genes related to the development and function of the CNS. Analysis of gene expression using gene ontology indicated that gene expression levels associated with apoptosis were altered in the brain of newborn pups, and those associated with brain development were altered in early age. The genes associated with response to oxidative stress were changed in the brains of two- and three-weekold mice. Changes to gene expression associated with neurotransmitters and psychiatric diseases were found (Shimizu et al. 2009). The results suggest the potential toxicity of nanoparticles on the development of newborns. Nano- $\mathrm{TiO}_{2}$ has also been shown to induce an increase in glial fibrillary acidic protein (GFAP), producing positive astrocytes in the CA4 region, which was in good agreement with higher Ti contents in the hippocampus region. This resulted in various types of oxidative stress in the brain of exposed mice such as lipid peroxidation, protein oxidation and increased activities of catalase, as well as the excessive release of glutamic acid and nitric oxide (Wang et al. 2008).

Nanotoxicology studies on the brain have also focused on fish. For example, in the brain of juvenile largemouth bass, a significant increase in lipid peroxidation was observed due to exposure to fullerenes (C60; $0.5 \times 10^{-6} \mathrm{~g} \mathrm{ml}^{-1} ; \quad$ Oberdörster 2004). In addition, it is conceivable that colloidal fullerenes need to be transported to lipid-rich regions (e.g. brain) before the colloid dissociates and frees individual redox-active fullerenes. It is also possible that there may be an inflammatory response creating reactive oxygen species (ROS) or that a reactive fullerene metabolite is produced. The actual mechanism still needs to be 


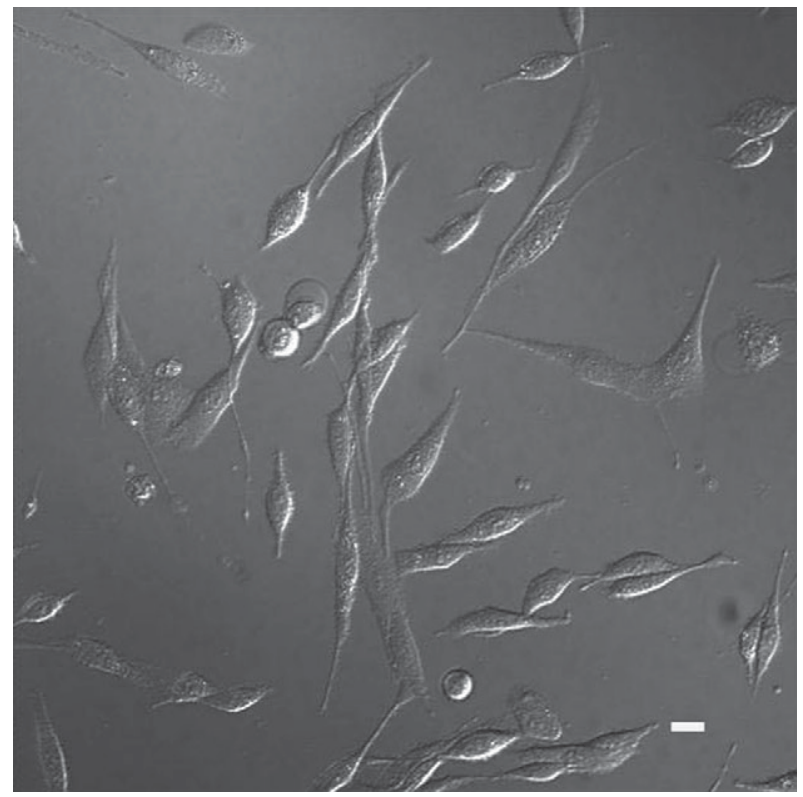

Figure 6. Confocal image of $\mathrm{PC}-12$ cells used in toxicity studies. The cell lengths are approximately $25-30 \mu \mathrm{m}$ under the confocal microscope before cell-line proliferation. However, after the cell division their lengths could grow up to several hundred micrometres (scale bar, $10 \mu \mathrm{m}$ ).

determined, and future research will focus on this question. The depletion of glutathione (GSH) is used as an indication of oxyradical scavenging ability, showing that the antioxidant defence system is overwhelmed by ROS (Oberdörster 2004).

Recent research has focused on the effects of nanoparticles on the BBB. According to a study by Sharma et al. (2010), administration of $\mathrm{Ag}, \mathrm{Cu}$ or $\mathrm{Al} / \mathrm{Al}_{2} \mathrm{O}_{3}$ nanoparticles showed disrupted $\mathrm{BBB}$ function and induced brain oedema formation. Moreover, silver nanoparticles induced BBB destruction and astrocyte swelling, and caused neuronal degeneration (Tang et al. 2009).

\subsection{Neurotoxicity research of nanoscaled materials in vitro}

Several studies have focused on PC-12 cells, a neuroendocrine cell line with the capability to produce the neurotransmitter DA and contain functional DA metabolism pathways (figure 6). Normal PC-12 cells are around 25-30 $\mu \mathrm{m}$; after cell division this could increase to several hundred micrometres. However, with exposure of PC-12 cells to Mn nanoparticles (40 nm), or $\mathrm{Mn}^{2+}$ (acetate), or $\mathrm{Ag}$ nanoparticles $(15 \mathrm{~nm})$ for $24 \mathrm{~h}$, the cells showed contrasting results. Phase-contrast microscopy studies show that exposure to $\mathrm{Mn}$ particles or $\mathrm{Mn}^{2+}$ does not greatly change the morphology of PC-12 cells. But exposure to Ag particles caused cell shrinkage plus irregular membrane borders compared with the control cells. Further microscopic studies at higher resolution microscopy revealed that $\mathrm{Mn}$ nanoparticles and agglomerates were effectively internalized by PC-12 cells (Hussain et al. 2006a,b). Mitochondrial reduction activity, a sensitive measure of particle and metal cytotoxicity, showed only moderate toxicity for $\mathrm{Mn}$ compared with similar $\mathrm{Ag}$ and $\mathrm{Mn}^{2+}$ doses. Mn particles and $\mathrm{Mn}^{2+}$ ions depleted DA (dose dependent) and its metabolites, dihydroxyphenylacetic acid (DOPAC) and homovanillic acid (HVA). Ag particles significantly reduced DA and DOPAC only at concentrations of $50 \mathrm{mg} \mathrm{ml}^{-1}$. Therefore, DA depletion due to Mn particles was most similar to $\mathrm{Mn}^{2+}$ ions, which is known to induce concentration-dependent DA depletion. The significant increase in ROS with Mn particle exposure also suggests that the increased ROS levels may participate in DA depletion (Hussain et al. 2006a). In another study, the expression of 11 genes associated with the dopaminergic system was examined using real-time reverse transcription polymerase chain reaction (RT-PCR). The results indicated that the expression of Txnrd1 was upregulated after the $\mathrm{Cu}-90$ treatment and the expression of Gpx1 was downregulated after Ag-15 or Cu-90 treatment. These alterations are consistent with the oxidative stress induced by metal nanoparticles. Mn40 induced a downregulation of the expression of Th; $\mathrm{Cu}-90$ induced an upregulation of the expression of MAOA. Mn-40 also induced a downregulation of the expression of Park2; while the expression of SNCA was upregulated after $\mathrm{Mn}-40$ or $\mathrm{Cu}-90$ treatment (Wang et al. 2009).

PC-12 cells have also been treated with different concentrations of $\mathrm{TiO}_{2}$ nanoparticles (1, 10, 50 and $100 \times 10^{-6} \mathrm{~g} \mathrm{ml}^{-1}$ ) and the viability of these cells was significantly reduced, showing a significant dose- and time-dependent effect (Liu et al. 2010). In agreement with earlier findings (Hussain et al. 2006a,b), the flow cytometric assay gave an indication that the $\mathrm{TiO}_{2}$ nanoparticles induced intracellular accumulation of ROS (as shown in figure 7) and apoptosis of the PC-12 cells with increasing concentration of $\mathrm{TiO}_{2}$. Interestingly, pre-treatment with a ROS scavenger could inhibit PC-12 apoptosis induced by the particles (Liu et al. 2010). Similar findings have been reported by Long et al. (2006), where $\mathrm{TiO}_{2}$ stimulated immediate ROS production.

Zinc ( $\mathrm{Zn})$ and Iron (Fe) nanoparticles have also been assessed for their cell interactions using a glioma cell line, A-172. Zn (300 nm), Fe (100 nm), Si (10-20, $\left.40-50,90-110 \mathrm{~nm} ; 0.24-2400 \times 10^{-9} \mathrm{~g} \mathrm{ml}^{-1}\right)$ and a micro-sized $(45 \mu \mathrm{m})$ Si (control) were analysed and used in cell cytotoxicity (Cha \& Myung 2007). Fluorescence was absent inside the glioma cell line A-172, suggesting that nanoparticles did not alter the membrane permeability and the cytotoxicity of nanoparticles in vitro was low, and it was not dependent on the types and sizes of nanoparticles, showing a low level of toxicity in vivo (Zhao et al. 2009). Here, the toxicity was due to material chemistry rather than size (Cha \& Myung 2007). Results obtained using reduced nanoparticle concentrations $\left(0.24-2400 \times 10^{-9} \mathrm{~g} \mathrm{ml}^{-1}\right) \quad$ compared with other studies (Hussain et al. 2006a; Liu et al. 2009) suggest that concentration is an important parameter when assessing exposure to cells.

In a separate study, up to $30 \mu \mathrm{g} \mathrm{ml}^{-1}$ single-walled CNTs (SWCNTs) significantly decreased the overall DNA content in chicken embryonic spinal cord or 


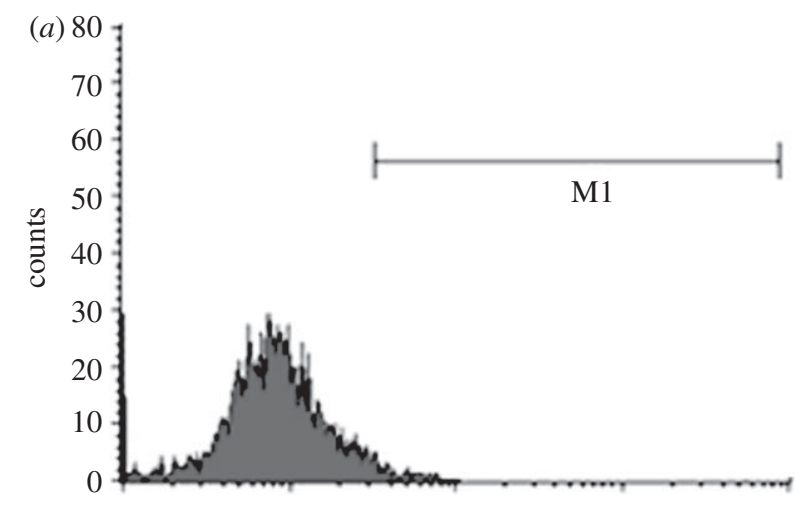

(b)
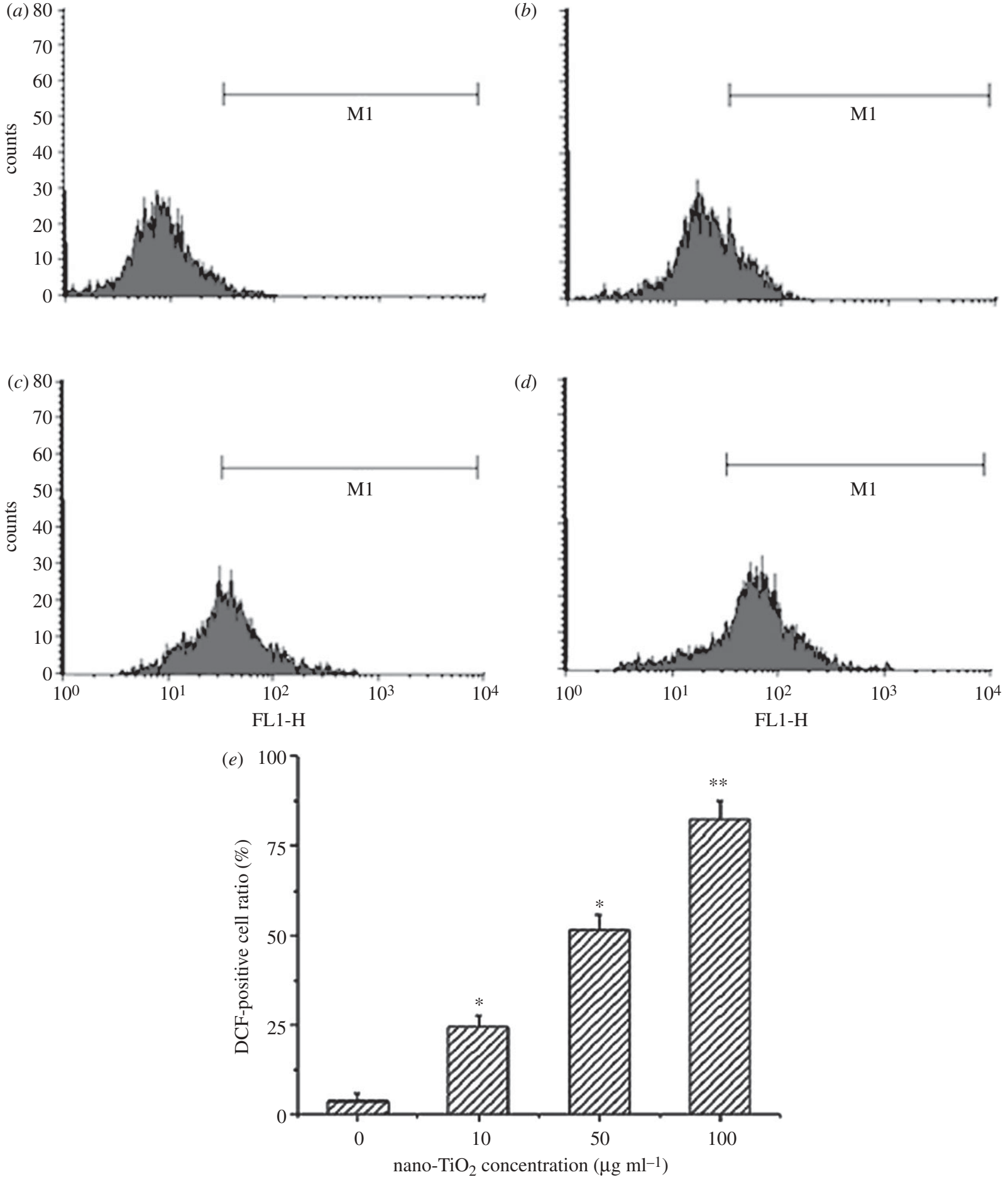

Figure 7. Measurement of ROS generation in PC-12 cells by flow cytometry. The cells were cultured with nano- $\mathrm{TiO}_{2}$ at concentrations of $(a) 0 \mu \mathrm{g} \mathrm{ml}^{-1}$, (b) $10 \mu \mathrm{g} \mathrm{ml}^{-1}$, (c) $50 \mu \mathrm{g} \mathrm{ml}^{-1}$ and $(d) 100 \mu \mathrm{g} \mathrm{ml}{ }^{-1}$ for $24 \mathrm{~h}$. ROS levels are dose dependent. The corresponding linear diagram of flow cytometry is shown $(e) . n=3$; mean \pm SEM; *statistically significant difference compared with controls $(p<0.05) ;{ }^{* *} p<0.01$ (Liu et al. 2010).

dorsal root ganglia. This effect was more pronounced when cells were exposed to highly agglomerated SWCNTs than when they were exposed to better dispersed SWCNT bundles (Belyanskaya et al. 2009).

\subsection{The patch clamp technique}

The patch clamp technique is a laboratory technique in electrophysiology that allows the study of single or multiple ion channels in cells. The technique can be applied to the study of excitable cells such as neurons, cardiomyocytes, muscle fibres and pancreatic beta cells.

This technique has been used in studying the effects of nanoparticles on ion channels (Zhao et al. 2009). This can be demonstrated using single rat hippocampal pyramidal neurons, isolated by enzymatic digestion and mechanical dispersion (according to the method of 

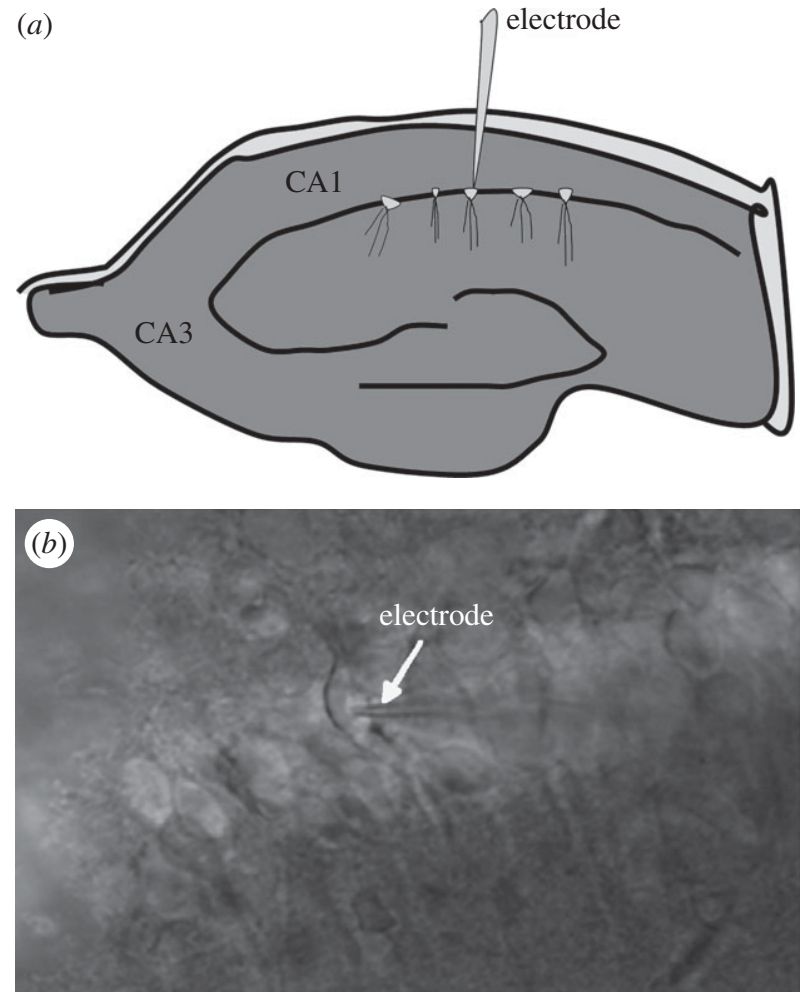

Figure 8. (a) Schematic diagram of hippocampal CA1 pyramidal neurons in the brain. (b) Whole cell patch clamp recording in CA1 pyramidal neuron from 14-18 Wistar rats.

Zou et al. 2000). Sample preparation includes slicing the entire hippocampus and subiculum horizontally $(400 \mu \mathrm{m}$ in thickness) using a vibratome (VT1000M/E, Leica, Germany) and incubating with artificial CSF (ACSF). Hippocampal CA1 neurons were then visualized on a monitor connected to a low light-sensitive charge-coupled device camera (figure 8; Liu et al. 2009).

Whole-cell currents of pyramidal neurons were recorded using an EPC10 patch clamp amplifier (HEKA, Germany; figure 9). After the rupture of the membrane and the establishment of a whole cell voltage-clamp configuration, compensation (80\%) for series resistance was routinely used. These data were low-pass filtered at $2.9 \mathrm{kHz}$, digitized at $10 \mathrm{kHz}$ (fourpole Bessel filter) and used Pulse 8.74 software (HEKA, Germany) at the ambient temperature $\left(21-23^{\circ} \mathrm{C}\right)$. The effect of metal nanoparticles on voltage-gated channels (hippocampal neurons) can be shown using $\mathrm{ZnO}$ nanoparticles (concentration of $10^{-4} \mathrm{~g} \mathrm{ml}^{-1}$; Zhao et al. 2009). Here, the transient outward potassium current $\left(I_{\mathrm{A}}\right)$ and delayed rectifier potassium current $\left(I_{\mathrm{K}}\right)$ increased considerably (figure 10). However, it is apparent that the $\mathrm{ZnO}$ solution/suspension did not shift the steady-state activation curve of $I_{\mathrm{A}}$ and $I_{\mathrm{K}}$, and nor did it have a significant effect on the inactivation and the recovery from the inactivation of $I_{\mathrm{A}}$. Peak amplitude and overshoot of the evoked single action potential was increased and the half-width was diminished in the presence of the $10^{-4} \mathrm{~g} \mathrm{ml}^{-1} \mathrm{ZnO}$ solution (Zhao et al. 2009). Using different nanoparticles, such as $\mathrm{CuO}$, other studies (Xu et al. 2009) have shown that $\mathrm{CuO}$ nanoparticles

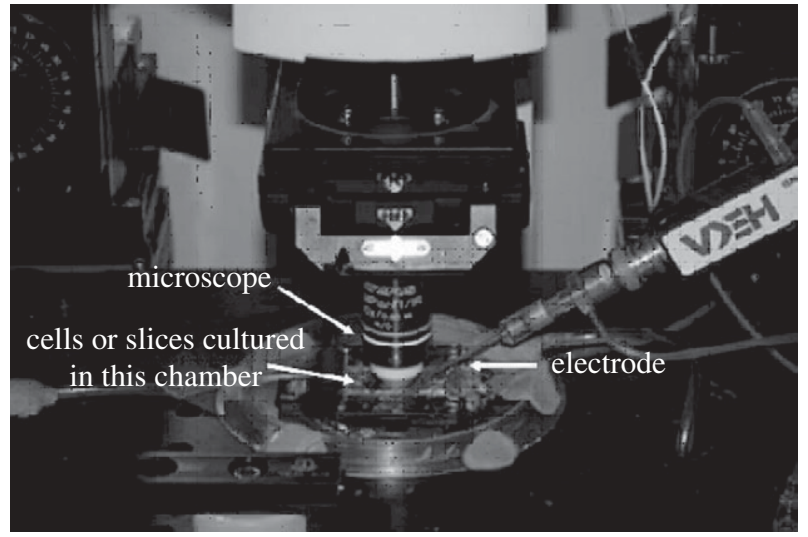

Figure 9. Experimental set-up for recording the response of neuron cells in ion channel currents.

$\left(5 \times 10^{-5} \mathrm{~g} \mathrm{ml}^{-1}\right)$ have no effects on $I_{\mathrm{A}}$, but inhibited $I_{\mathrm{K}}$ (figure 10). Furthermore, $\mathrm{CuO}$ nanoparticles did not shift the steady-state activation curve of $I_{\mathrm{K}}$ and $I_{\mathrm{A}}$, but the inactivation curve of $I_{\mathrm{K}}$ was shifted negatively. The effects on the inactivation curve of $I_{\mathrm{A}}$ have no statistical significance (Xu et al. 2009).

More recent work (Xu et al. 2009) demonstrated that $\mathrm{ZnO}$ nanoparticles increase the peak amplitudes of the voltage-gated sodium current $\left(I_{\mathrm{Na}}\right.$; figure 11$)$, while the inactivation and the recovery from inactivation of the $I_{\mathrm{Na}}$ are promoted by $\mathrm{ZnO}$. The data also show that the steady-state activation curve of the $I_{\mathrm{Na}}$ has not been shifted by $\mathrm{ZnO}$ nanoparticles. When the effects of $\mathrm{Ag}$ nanoparticles on the $I_{\mathrm{Na}}$ were examined with increasing concentrations $\left(10^{-6}, 5 \times 10^{-6}\right.$, $10^{-5} \mathrm{~g} \mathrm{ml}^{-1}$ ), the results revealed that only concentrations of $10^{-5} \mathrm{~g} \mathrm{ml}^{-1}$ reduced the amplitude of the $I_{\mathrm{Na}}$ (figure 11). Similar to $\mathrm{ZnO}, \mathrm{Ag}$ particles produced a hyperpolarizing shift in the activation-voltage curve of $I_{\mathrm{Na}}$. Ag nanoparticles delay the recovery of the $I_{\mathrm{Na}}$ from inactivation (Liu et al. 2009), but the $\mathrm{ZnO}$ accelerates the process (Zhao et al. 2009).

$\mathrm{ZnO}$ also increases the evoked single action potential and repetitive firing rate. Action potentials are a fundamental property of excitable cells in the mammalian CNS. ZnO enhances peak amplitude and overshoot and demonstrates decreased half-width of the evoked single action potential. Conversely, peak amplitude and overshoot of the evoked single action potential are decreased and half-width is increased in the presence of a $10^{-5} \mathrm{~g} \mathrm{ml}^{-1} \mathrm{Ag}$ nanoparticle solution (Liu et al. 2009).

\section{CONCLUSION}

In conclusion, most studies on the interaction between CNS neuronal cells and nanoparticles have used metal or metal oxides (including $\mathrm{Cu}, \mathrm{CuO}, \mathrm{Zn}$ and $\mathrm{Ag}$ ) with selected neuronal cell lines (PC-12, CA1 and CA3). Neurologists have an interest in both functionality and toxicity with regard to the effects of nanoparticles, with the more recent studies focussing on the interaction with hippocampal cell membranes, as carried out for CNS drug toxicity. The effects of nanomaterials 

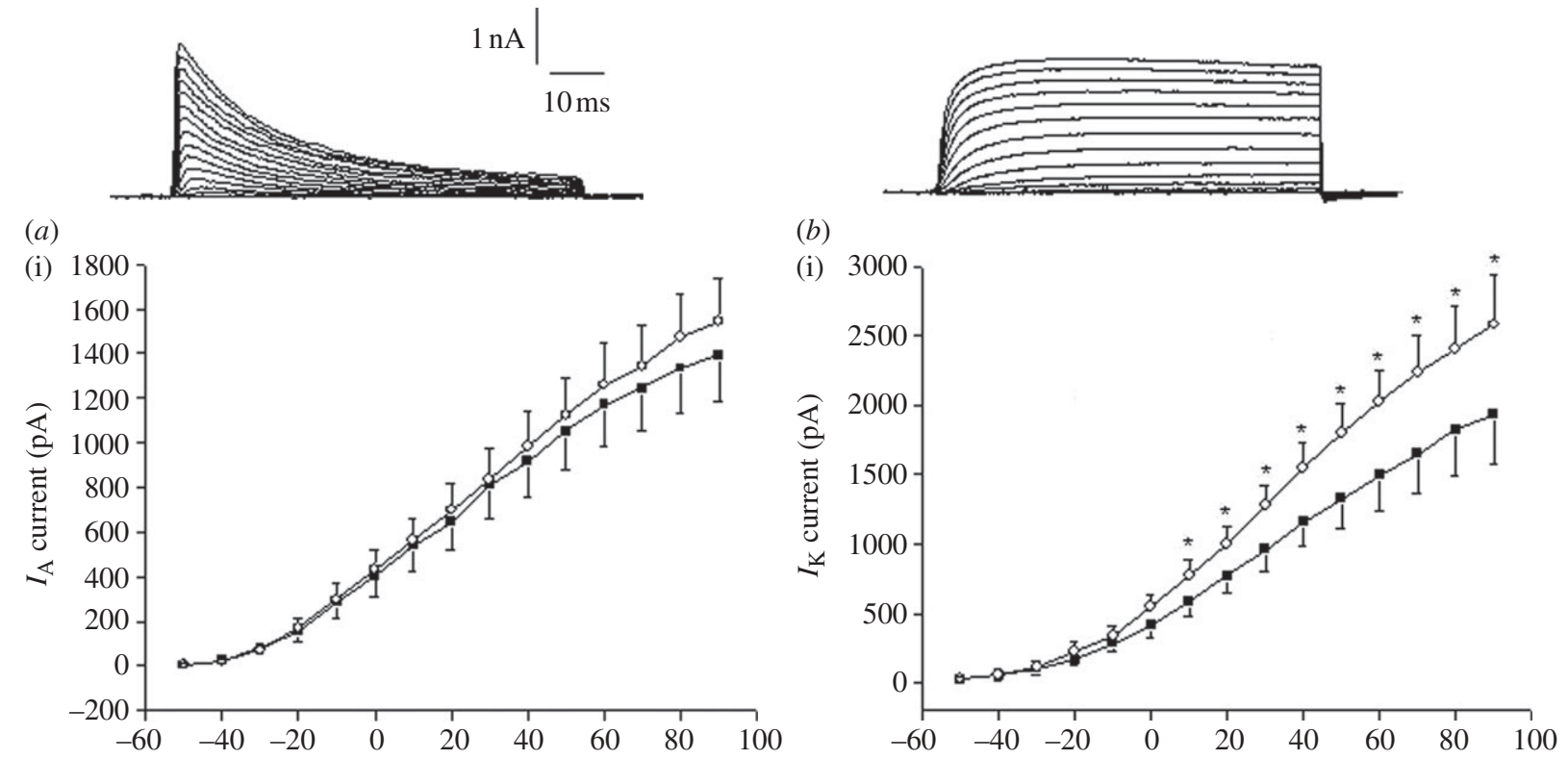

(ii)

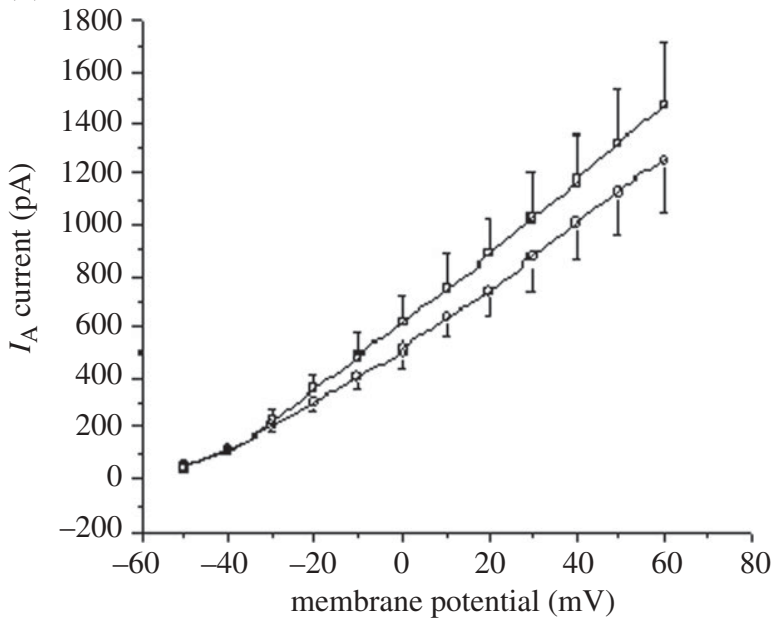

(ii)

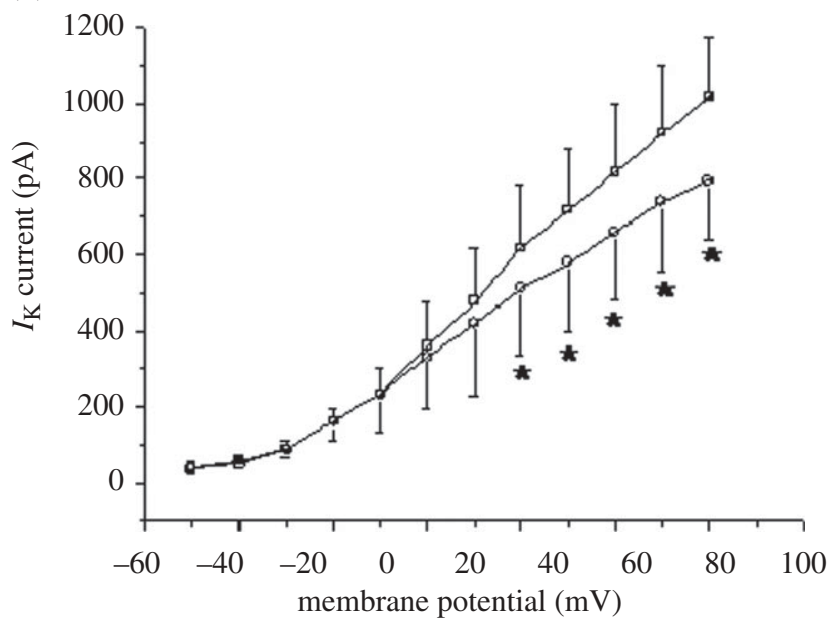

Figure 10. The original traces of $(a)(\mathrm{i})(\mathrm{ii}) I_{\mathrm{A}}$ and $(b)(\mathrm{i})(\mathrm{ii}) I_{\mathrm{K}}$. The contrasting effects of $\mathrm{ZnO}$ and $\mathrm{CuO}$ nanoparticles on $I-V$ currents and peak amplitudes of $I_{\mathrm{A}}$ and $I_{\mathrm{K}}$ on hippocampal pyramidal neurons from Wistar rats (Xu et al. 2009; Zhao et al. 2009). (a,b) (i) Filled square, control; open circle, nano-ZnO; $(a, b)$ (ii) open square, control; open circle, nano-CuO.

on ion channels within neurons may specifically relate to $\mathrm{Na}^{+}\left[I_{\mathrm{Na}}(\mathrm{A})\right]$ and $\mathrm{K}^{+}\left[I_{\mathrm{K}}(\mathrm{A})\right]$ channels, as shown by a number of studies. It is possible that such ion channel effects may not apply to some other nanoparticles such as gold, which has been reported to possess unique biological properties and positive functionalities.

Neurologists have an equal interest in both areas of positive functionality and negative toxicity of nanoparticles on the human neuron cells as well as the interactions when passing through the BBB. Studies now have focused on biological membranes on the hippocampal cells, as carried out previously for drug toxicities within the CNS.

The range of applications continues to grow for nanomaterials at a rapid rate. The potential of individual nanoparticles and carbon nanotubes as constituents of toothpastes, beauty products, sunscreens, coatings, drug delivery systems, sensors, building materials, and textiles are being explored. Thus, a complete understanding of the mechanisms of interaction between nanoparticles and target cells that may lead to local and systemic effects within the CNS is required.

\section{FUTURE RESEARCH WORK AND POTENTIAL RESEARCH DIRECTIONS}

Nanotoxicity research can be applied to a number of applications, such as determining composition levels in coatings for medical devices, medical-grade sheet moulding compounds for hospital equipment, aircraft filter fabrics, printing-coat films/inks and compositions for high-performance aviation gas turbine lubricants.

The direction provided from previous work on functionality/nanotoxicity of nanoparticles on CNS cells should be focused towards further understanding the mechanism of action, and their neurological and circulatory effects using animal and in vitro models. Rat 

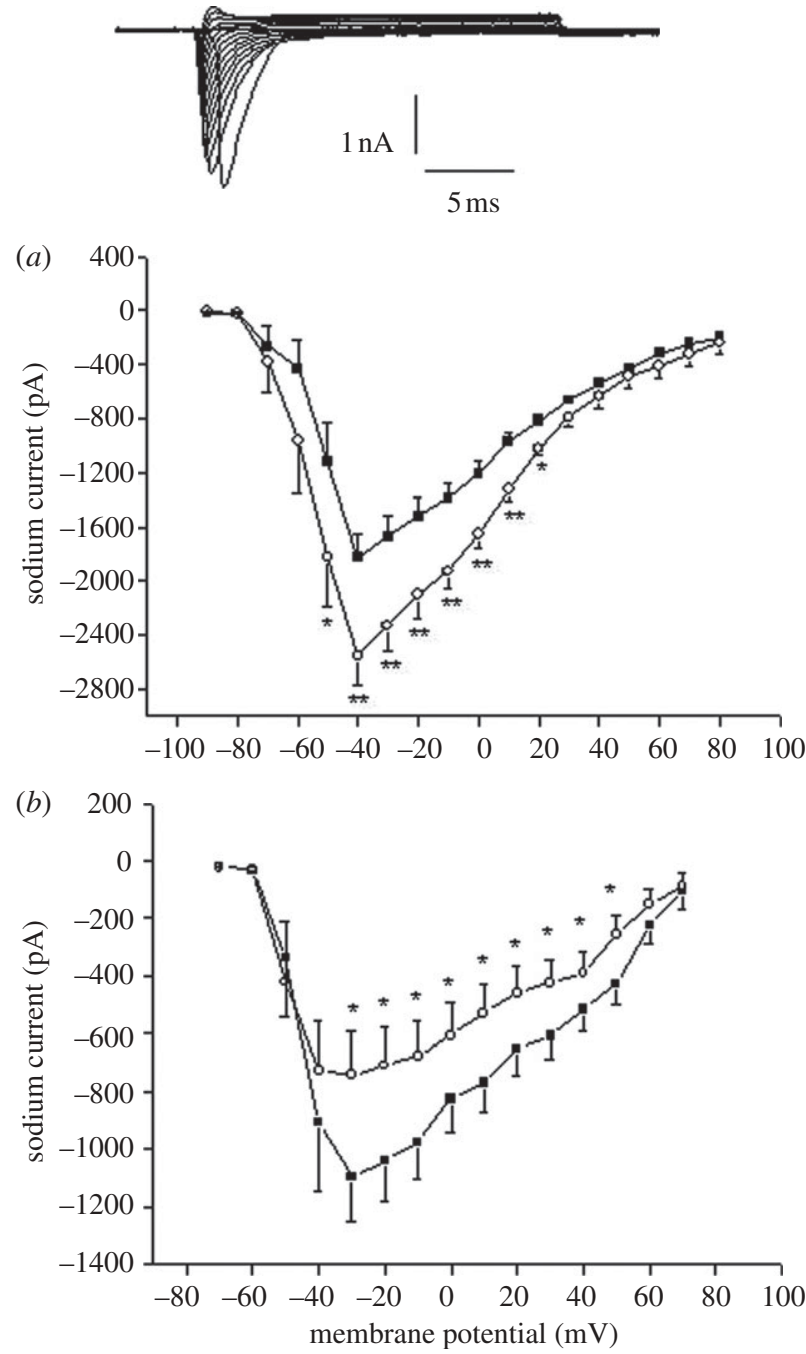

Figure 11. The original traces of the $I_{\mathrm{Na}}$. (a) The increased effects of the nano- $\mathrm{ZnO}$ (filled square, control; open circle, nano- $\mathrm{ZnO}$ ) and (b) decreased effects of nano-Ag on $I-V$ currents and peak amplitudes of $I_{\mathrm{Na}}$ on hippocampal pyramidal neurons from Wistar rats (Liu et al. 2009; Zhao et al. 2009 filled square, control; open circle, nano-Ag).

models, such as ischaemia, vascular dementia, epilepsy and diffuse axonal injury, are the first step for further assessment of functionality. Methods to address current problems in such tests also need to be developed. The existing problems in biological tests include nanoparticle agglomeration and aggregation within both liquid and airborne forms. In particular, nanoparticle dispersion in air with different sizes, materials and morphologies with controlled agglomeration involving aerosol delivery for in vivo and in vitro studies is the most challenging work in the field of nanoparticle toxicology due to difficulties in nanoparticle measurements, generation and observation (Kim et al. 2010), although some technological advances have been made on the proof of concept stage.

Also, the current knowledge on engineered nanoparticles and their interactions with the CNS cells is extremely limited and traditional drug toxicology studies may not be ideal models to draw comparison with due to the special nanofunctions and features. Further research on nanotoxicity as well as functionality will allow the expansion of the much needed understanding in this area, with a build-up of the physical and chemical properties of nanostructures influencing in vivo and in vitro behaviour towards CNS neural cells. In the CNS, microglial cells are a type of macrophage found in the brain, and they may be involved in handling any nanoparticles that reach the brain, and these cellular responses to nanoparticles should be investigated. Biological (CNS cells) interactions linked to particle size, surface energy, composition and aggregation will form a focal point of some future studies. Many biological properties of nanoparticles (i.e. $\mathrm{Ag}, \mathrm{Cu}, \mathrm{Fe}_{2} \mathrm{O}_{3}, \mathrm{Al}_{2} \mathrm{O}_{3}, \mathrm{ZnO}, \mathrm{SiO}_{2}, \mathrm{TiO}_{2}$, $\mathrm{CuO}, \mathrm{Cu}_{2} \mathrm{O}$, and $\mathrm{WC}$, etc.) have been investigated in terms of the aetiology, pathology, physiology and epidemiology; however, no report has been obtained on CNS neurons owing to the complexity and high costs associated with assessments.

This future work will be supported by a grant from the UK Royal Academy of Engineering (ref. 5502) on a Major Research Exchanges Award.

\section{REFERENCES}

Allaker, R. P. \& Ren, G. 2008 Potential impact of nanotechnology on the control of infectious diseases. Trans. R. Soc. Trop. Med. Hygiene 102, 1-2. (doi:10.1016/j.trstmh.2007. 07.003)

Au, C., Mutkus, L., Dobson, A., Riffle, J., Lalli, J. \& Aschner, M. 2007 Effects of nanoparticles on the adhesion and cell viability on astrocytes. Biol. Trace Elem. Res. 120, 248-256. (doi:10.1007/s12011-007-0067-z)

Belyanskaya, L., Weigel, S., Hirsch, C., Tobler, U., Krug, H. F. \& Wick, P. 2009 Effects of carbon nanotubes on primary neurons and glial cells. Neurotoxicology 30, 702-711. (doi:10.1016/j.neuro.2009.05.005)

Brooking, J., Davis, S. S. \& Illum, L. 2001 Transport of nanoparticles across the rat nasal mucosa. J. Drug Targeting $\mathbf{9}$, 267-279. (doi:10.3109/10611860108997935)

Cha, K. E. \& Myung, H. 2007 Cytotoxic effects of nanoparticles assessed in vitro and in vivo. J. Microbial Biotechnol. 17, 1573-1578.

Cha, K., Hong, H. W., Choi, Y. G., Lee, M. J., Park, J. H., Chae, H. K., Ryu, G. \& Myung, H. 2008 Comparison of acute responses of mice livers to short-term exposure to nano-sized or micro-sized silver particles. Biotechnol. Lett. 30, 1893-1899. (doi:10.1007/s10529-008-9786-2)

Chen, J., Han, C. M., Lin, X. W., Tang, Z. J. \& Su, S. J. 2006 Effect of silver nanoparticle dressing on second degree burn wound. Zhonghua Wai Ke Za Zhi 44, 50-52.

Chunfu, Z., Jinquan, C., Duanzhi, Y., Yongxian, W., Yanlin, F. \& Jiaju, T. 2004 Preparation and radiolabeling of human serum albumin (HSA)-coated magnetite nanoparticles for magnetically targeted therapy. Appl. Radiat. Isot. 61, 1255-1259. (doi:10.1016/j.apradiso.2004.03.114)

Cole, J. C. \& Sumnall, H. R. 2003 Altered states: the clinical effects of ecstasy. Pharmacol. Ther. 98, 35-58. (doi:10. 1016/S0163-7258(03)00003-2)

De Jong, W. H. \& Borm, P. J. 2008 Drug delivery and nanoparticles: applications and hazards. Int. J. Nanomed. 3, $133-149$.

Gatti, A. M., Montanari, S., Monari, E., Gambarelli, A., Capitani, F. \& Parisini, B. 2004 Detection of micro- and nano-sized biocompatible particles in the blood. J. Mater. 
Sci. Mater. Med. 15, 469-472. (doi:10.1023/B:JMSM. 0000021122.49966.6d)

Guo, F., Yu, N., Cai, J. Q., Quinn, T., Zong, Z. H., Zeng, Y. J. \& Hao, L. Y. 2008 Voltage-gated sodium channels Nav1.1, Nav1.3 and $\beta 1$ subunit were up-regulated in the hippocampus of spontaneously epileptic rat. Brain Res. Bull. 75, 179-187. (doi:10.1016/j.brainresbull.2007.10.005)

Hoet, P. H., Bruske-Hohlfeld, I. \& Salata, O. V. 2004 Nanoparticles - known and unknown health risks. J. Nanobiotechnol. 2, 12. (doi:10.1186/1477-3155-2-12)

Hussain, S. M., Javorina, A. K., Schrand, A. M., Duhart, H. M., Ali, S. F. \& Schlager, J. J. $2006 a$ The interaction of manganese nanoparticles with PC-12 cells induces dopamine depletion. Toxicol. Sci. 92, 456-463. (doi:10.1093/ toxsci/kfl020)

Hussain, S. M., Javorina, A. K., Schrand, A. M., Duhart, H. M., Ali, S. F. \& Schlager, J. J. $2006 b$ The interaction of manganese nanoparticles with PC-12 cells induces dopamine depletion. Toxicol. Sci. 92, 456-463. (doi:10. 1093/toxsci/kfl020)

Kim, J. S. et al. 2006 Toxicity and tissue distribution of magnetic nanoparticles in mice. Toxicol. Sci. 89, 338-347. (doi:10.1093/toxsci/kfj027)

Kim, K. J., Sung, W. S., Suh, B. K., Moon, S. K., Choi, J. S., Kim, J. G. \& Lee, D. G. 2009 Antifungal activity and mode of action of silver nano-particles on Candida albicans. Biometals 22, 235-242. (doi:10.1007/s10534-008-9159-2)

Kim, S. C., Chen, D.-R., Qi, C., Gelein, R. M., Finkelstein, J. N., Elder, A., Bentley, K., Oberdörster, G. \& Pui, D. Y. H. 2010 A nanoparticle dispersion method for in vitro and in vivo nanotoxicity study. Nanotoxicology $\mathbf{4}$, 42-51. (doi:10.3109/17435390903374019)

Kirkpatrick, C. J. \& Bonfield, W. 2010 NanoBioInterface: a multidisciplinary challenge. J. R. Soc. Interface $\mathbf{7}$, S1-S4. (doi:10.1098/rsif.2009.0489.focus)

Lecoanet, H. F., Bottero, J. Y. \& Wiesner, M. R. 2004 Laboratory assessment of the mobility of nanomaterials in porous media. Environ. Sci. Technol. 38, 5164-5169. (doi:10. 1021/es0352303)

Liu, Z., Ren, G., Zhang, T. \& Yang, Z. 2009 Action potential changes associated with the inhibitory effects on voltagegated sodium current of hippocampal CA1 neurons by silver nanoparticles. Toxicology 264, 179-184. (doi:10. 1016/j.tox.2009.08.005)

Liu, S., Xu, L., Zhang, T., Ren, G. \& Yang, Z. 2010 Oxidative stress and apoptosis induced by nanosized titanium dioxide in PC12 cells. Toxicology 267, 172-177. (doi:10. 1016/j.tox.2009.11.012)

Long, T. C., Saleh, N., Tilton, R. D., Lowry, G. V. \& Veronesi, B. 2006 Titanium dioxide (P25) produces reactive oxygen species in immortalized brain microglia (BV2): implications for nanoparticle neurotoxicity. Environ. Sci. Technol. 40, 4346-4352. (doi:10.1021/es060589n)

Lu, S., Gao, W. \& Gu, H. Y. 2008 Construction, application and biosafety of silver nanocrystalline chitosan wound dressing. Burns 34, 623-628. (doi:10.1016/j.burns.2007. 08.020)

Meisler, M. H. \& Kearney, J. A. 2005 Sodium channel mutations in epilepsy and other neurological disorders. J. Clin. Invest. 115, 2010-2017. (doi:10.1172/JCI25466)

Moore, W. R., Graves, S. E. \& Bain, G. I. 2001 Synthetic bone graft substitutes. ANZ J. Surg. 71, 354-361. (doi:10.1046/ j.1440-1622.2001.02128.x)

Muthu, M. S. \& Singh, S. 2009 Targeted nanomedicines: effective treatment modalities for cancer, AIDS and brain disorders. Nanomedicine (Lond.) 4, 105-118. (doi:10. $2217 / 17435889.4 .1 .105)$
Oberdörster, E. 2004 Manufactured nanomaterials (fullerenes, C60) induce oxidative stress in the brain of juvenile largemouth bass. Environ. Health Perspect. 112, $1058-1062$

Oberdörster, G. et al. \& ILSI Research Foundation/Risk Science Institute Nanomaterial Toxicity Screening Working Group. 2005 Review: principles for characterizing the potential human health effects from exposure to nanomaterials elements of a screening strategy. Part. Fibre Toxicol. 2, 8. (doi:10.1186/1743-8977-2-8)

Panyala, N. R., Pena-Mendez, E. M. \& Havel, J. 2008 Silver or silver nanoparticles: a hazardous threat to the environment and human health? J. Appl. Biomed. 6, 117-129.

Raffi, M., Hussain, F., Bhatti, T. M., Akhter, J. I., Hameed, A. \& Hasan, M. M. 2008 Antibacterial characterization of silver nanoparticles against. J. Mater. Sci. Technol. 24, 192-196.

Robichaud, C. O., Tanzil, D., Weilenmann, U. \& Wiesner, M. R. 2005 Relative risk analysis of several manufactured nanomaterials: an insurance industry context. Environ. Sci. Technol. 39, 8985-8994. (doi:10.1021/es0506509)

Royal Academy of Engineering 2004 Nanotechnology: views of the general public. Quantitative and qualitative research carried out as part of the Nanotechnology Study. BMRB Social Research Report for the Royal Society and Royal Academy of Engineering Nanotechnology Working Group, BMRB/45/101-666. London, UK: BMRB Social Research.

Rungby, J. \& Danscher, G. 1983 Localization of exogenous silver in brain and spinal cord of silver exposed rats. Acta Neuropathol. 60, 92-98. (doi:10.1007/BF00685352)

Sarin, H. et al. 2008 Effective transvascular delivery of nanoparticles across the blood-brain tumor barrier into malignant glioma cells. J. Transl. Med. 6, 80. (doi:10. 1186/1479-5876-6-80)

Sarlo, K. et al. 2009 Tissue distribution of $20 \mathrm{~nm}, 100 \mathrm{~nm}$ and $1000 \mathrm{~nm}$ fluorescent polystyrene latex nanospheres following acute systemic or acute and repeat airway exposure in the rat. Toxicology 263, 117-126. (doi:10.1016/j.tox. 2009.07.002)

Seaton, A., Tran, L., Aitken, R. \& Donaldson, K. 2010 Nanoparticles, human health hazard and regulation. J. R. Soc. Interface 7, S119-S129. (doi:10.1098/rsif.2009.0252.focus)

Seeman, N. C. 2006 DNA enables nanoscale control of the structure of matter. Q. Rev. Biophys. 6, 1-9.

Seemayer, N. H., Hadnagy, W. \& Tomingas, T. 1990 Evaluation of health risks by airborne particulates from in vitro cyto- and genotoxicity testing on human and rodent tissue culture cells: a longitudinal study from 1975 until now. J. Aerosol. Sci. 21(Suppl. 1), 501-504. (doi:10.1016/0021-8502(90)90290-E)

Seidner, G. et al. 1998 GLUT-1 deficiency syndrome caused by haploinsufficiency of the blood-brain barrier hexose carrier. Nat. Genet. 18, 188-191. (doi:10.1038/ng0298-188)

Sharma, H. S. \& Sharma, A. 2007 Nanoparticles aggravate heat stress induced cognitive deficits, blood-brain barrier disruption, edema formation and brain pathology. Prog. Brain Res. 162, 245-273. (doi:10.1016/S00796123(06)62013-X)

Sharma, H. S., Hussain, S., Schlager, J., Ali, S. F. \& Sharma, A. 2010 Influence of nanoparticles on blood-brain barrier permeability and brain edema formation in rats. Acta Neurochir. Suppl. 106, 359-364. (doi:10.1007/978-3-21198811-4_65)

Shimizu, M., Tainaka, H., Oba, T., Mizuo, K., Umezawa, M. \& Takeda, K. 2009 Maternal exposure to nanoparticulate titanium dioxide during the prenatal period alters gene 
expression related to brain development in the mouse. Part. Fibre Toxicol. 6, 20. (doi:10.1186/1743-8977-6-20)

Shin, S. H., Ye, M. K., Kim, H. S. \& Kang, H. S. 2007 The effects of nano-silver on the proliferation and cytokine expression by peripheral blood mononuclear cells. Int. Immunopharmacol. 7, 1813-1818. (doi:10.1016/j.intimp. 2007.08.025)

Sun, H., Choy, T. S., Zhu, D. R., Yam, W. C. \& Fung, Y. S. 2009 Nano-silver-modified PQC/DNA biosensor for detecting E. coli in environmental water. Biosens. Bioelectron. 24, 1405-1410. (doi:10.1016/j.bios.2008.08.008)

Tang, M. et al. 2008 Unmodified CdSe quantum dots induce elevation of cytoplasmic calcium levels and impairment of functional properties of sodium channels in rat primary cultured hippocampal neurons. Environ. Health Perspect. 116, 915-922. (doi:10.1289/ehp.11225)

Tang, J., Xiong, L., Wang, S., Wang, J., Liu, L., Li, J., Yuan, F. \& Xi, T. 2009 Distribution, translocation and accumulation of silver nanoparticles in rats. J. Nanosci. Nanotechnol. 9, 4924-4932. (doi:10.1166/ jnn.2009.1269)

Thian, E. S. et al. 2008 The role of electrosprayed nanoapatites in guiding osteoblast behaviour. Biomaterials 29, 1833-1843. (doi:10.1016/j.biomaterials.2008.01.007)

Wang, J. et al. 2008 Potential neurological lesion after nasal instillation of $\mathrm{TiO}(2)$ nanoparticles in the anatase and rutile crystal phases. Toxicol. Lett. 183, 72-80. (doi:10. 1016/j.toxlet.2008.10.001)

Wang, J., Rahman, M. F., Duhart, H. M., Newport, G. D., Patterson, T. A., Murdock, R. C., Hussain, S. M., Schlager, J. J. \& Ali, S. F. 2009 Expression changes of dopaminergic system-related genes in PC12 cells induced by manganese, silver, or copper nanoparticles. Neurotoxicology 30, 926-933. (doi:10.1016/j.neuro.2009.09.005)

Warheit, D. B., Laurence, B. R., Reed, K. L., Roach, D. H., Reynolds, G. A. \& Webb, T. R. 2004 Comparative pulmonary toxicity assessment of single-wall carbon nanotubes in rats. Toxicol. Sci. $\mathbf{7 7}, 117-125$. (doi:10.1093/toxsci/ kfg228)

Xu, L. J., Zhao, J. X., Zhang, T., Ren, G. G. \& Yang, Z. 2009 In vitro study on influence of nano particles of $\mathrm{CuO}$ on CA1 pyramidal neurons of rat hippocampus potassium currents. Environ. Toxicol. 24, 211-217. (doi:10.1002/ tox.20418)

Zhao, J., Xu, L., Zhang, T., Ren, G. \& Yang, Z. 2009 Influences of nanoparticle zinc oxide on acutely isolated rat hippocampal CA3 pyramidal neurons. Neurotoxicology 30, 220-230. (doi:10.1016/j.neuro.2008.12.005)

Zou, B., Chen, Y., Wu, C. \& Zhou, P. 2000 Blockade of U50488H on sodium currents in acutely isolated mice hippocampal CA3 pyramidal neurons. Brain Res. 855, 132-136. (doi:10.1016/S0006-8993(99)02360-4) 